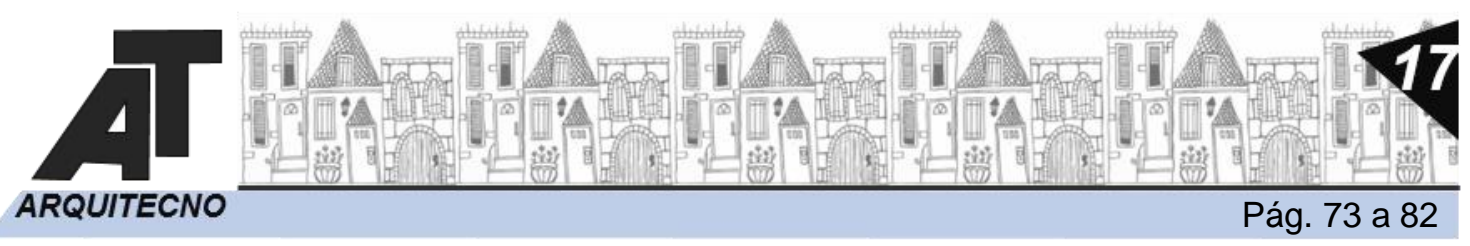

\title{
Los sistemas de enverdecimiento como expresión de la arquitectura bioinspirada y su incipiente aplicación en la Ciudad de Resistencia
}

\section{Greening systems as an expression of bio-inspired architecture and its incipient application in the City of Resistencia}

Florencia Belén Galizzi, Claudia Pilar y Daniel Vedoya

Instituto de Investigaciones Tecnológicas para el Diseño Ambiental del Hábitat Humano florenciagalizzi@hotmail.com, claudiapilar2014@gmail.com, devedoya@gmail.com

\section{RESUMEN}

El presente trabajo aborda la problemática de la envolvente edilicia considerando que su adecuado diseño es la principal herramienta para disminuir el consumo energético de los edificios y lograr de forma sustentable condiciones de confort en los espacios.

La envolvente conforma la separación entre el interior y exterior, proporcionando funciones de soporte, control, acabado y distribución de servicios. En su función de moderador ambiental, la incorporación del verde se convierte en una herramienta sumamente poderosa. Mediante la sistematización tecnológica-constructiva de los distintos Sistemas de Enverdecimiento (SE) se logra el estudio de los casos locales que presenta la Ciudad de Resistencia, para comprobar que su aplicación si bien se ha extendido en el mundo y comenzado en algunas regiones del país, es aún baja en la ciudad de Resistencia, Chaco, siendo los más utilizados los sistemas hidropónicos, enrejados modulares e incontables cuadros vivos.

\section{ABSTRACT}

The present work addresses the problem of the building envelope considering that its adequate design is the main tool to reduce energy consumption in buildings and achieve comfort conditions in spaces in a sustainable way.

The envelope forms the separation between the interior and exterior, providing support, control, finishing and service distribution functions. In your role as an environmental moderator, the incorporation of green becomes an extremely powerful tool. Through the technologicalconstructive systematization of the different Greening Systems (SE), the study of local cases presented by the City of Resistencia is achieved, to verify that its application has spread throughout the world and started in some regions of the country, is still low in the city of Resistencia, Chaco, being the most used hydroponic systems, modular trellises and countless living pictures.

PALABRAS CLAVES: envolvente natural, aislamiento térmico, sustentabilidad visual.

KEY WORDS: natural envelope, thermal isolation, visual sustainability.

FECHA DE RECEPCIÓN: 17/4/2021 | FECHA DE ACEPTACIÓN: 12/5/2021

DOI: http://dx.doi.org/10.30972/arq.0174985 


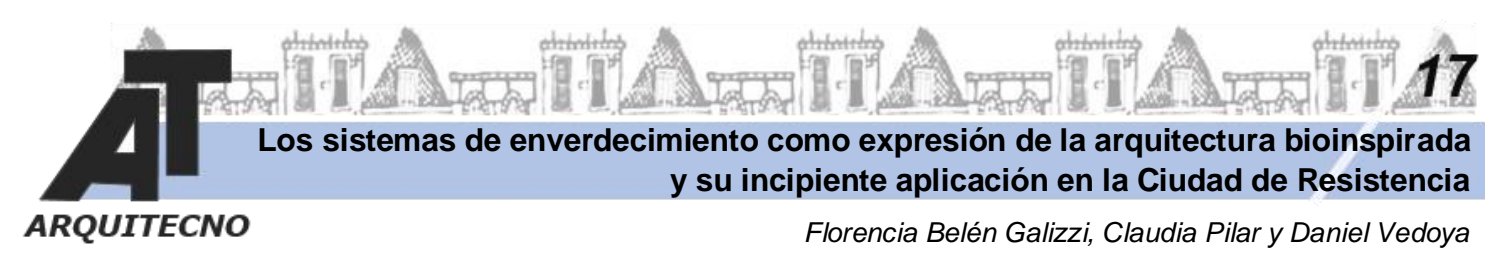

\section{INTRODUCCIÓN}

El presente trabajo aborda la problemática de la envolvente edilicia considerando que su adecuado diseño es la principal herramienta para disminuir el consumo energético de los edificios y lograr de forma sustentable condiciones de confort en los espacios.

En los últimos diez años la sociedad se ha enfrentado a múltiples problemáticas: crecimiento demográfico descontrolado, agotamiento de los recursos naturales, incontrolado calentamiento global, avance sobre el medio ambiente, destrucción de la biodiversidad, entre otros.

En Argentina, de acuerdo a Czajkowski (2009) el consumo energético en relación con otros países es sumamente alto y la calidad energética edilicia tiende a reducirse con el transcurso de los años. Esto quiere decir que las técnicas de habitabilidad higrotérmica y racionalidad energética no se encuentran desarrolladas o bien su aplicación continúa siendo muy baja.

\section{Arquitectura Bio-inspirada}

El ser humano desde sus inicios, basó sus innovaciones tecnológicas en la observación de la naturaleza, el aprender de ella y entenderla. El enfoque de la Arquitectura Bio-inspirada hace referencia a la manera en la cual los recursos brindados por el entorno le permiten al profesional (en este caso los arquitectos), resolver las necesidades de cobijo y protección complejizándolas con los requerimientos del confort.

La biomimética, como disciplina del diseño, es una rama de la ciencia que le aporta al hombre un método para resolver problemas. Permite aprender de las formas y procesos naturales, propiciando la creación o adecuación de soluciones tecnológicas cada vez más sostenibles y ambientalmente más conscientes. Ésta es de carácter eminentemente interdisciplinaria, dado que para comprender la naturaleza el método de abordaje debe ser holístico. En lo que atañe a la arquitectura, consecuentemente con estas problemáticas, se está orientando el esfuerzo hacia la búsqueda de soluciones de diseño más eficaces, proyectos más eficientes que puedan lograr un equilibrio entre lo humano y la naturaleza, etc., lo que ha dado lugar a una nueva tendencia que se conoce como Arquitectura Biomimética (de "bio" = vida, y "mimesis" = imitar).

En la actualidad el enfoque biomimético no pretende extraer cosas de la naturaleza, sino aprender de ella (Benyus, 2012). Concretamente, la Arquitectura Biomimética nos acerca a un diseño más natural, tomando en cuenta las estrategias y soluciones que utiliza la naturaleza, aplicándolas en varios aspectos, creando diseños más naturales, ahorrando y haciendo más eficiente el uso de los recursos, sin agotarlos (Vedoya y Prat, 2018).

De esta manera, la envolvente verde es cambiante como la naturaleza misma y transforma a los edificios en parte del paisaje que cambia de color con las estaciones, mejorando el microclima urbano, combatiendo la isla de calor, con los mecanismos evapotranspirativos de las plantas y aumentan la biodiversidad en el ámbito urbano.

El sector de la construcción es responsable del consumo de gran parte de los recursos naturales, los que en gran parte se convierten en residuos y emisiones liberadas. Un número considerable de obras y los componentes que conforman la misma se producen desde el enfoque "De la cuna a la tumba" (Braungart y Mcdonough, 2005), con materiales valiosos, en donde su extracción, producción, distribución, consumo y disposición no solo cuestan sumas exuberantes, sino que el destino final de los mismos es en vertederos o basureros a cielo abierto. Esta economía de los materiales presenta un sistema lineal, el cual claramente no funciona no solo porque el mundo es finito y se dejan de lado multiplicidad de factores, sino porque además no se tiene en cuenta el ciclo de vida de los materiales. Lo que se pretende es diseñar productos y sistemas que celebren la abundancia de la creatividad, la cultura y la productividad humana. Pero también es factible concebir los productos de manera inteligente con el propósito de que al final de la vida 
Los sistemas de enverdecimiento como expresión de la arquitectura bioinspirada y su incipiente aplicación en la Ciudad de Resistencia

Florencia Belén Galizzi, Claudia Pilar y Daniel Vedoya

útil, reingrese a la naturaleza como nutriente biológico, o se reinserte en la tecnosfera como nutriente técnico, en el paradigma circular "De la cuna a la cuna" (Braungart y Mcdonough, 2005),

\section{Los Sistemas de Enverdecimiento (SE) y sus ventajas}

Como estrategia de aprovechamiento pasivo, se plantea la incorporación del verde en fachadas, dado que constituyen la piel a través de la cual los edificios realizan su intercambio energético entre el ambiente interior y exterior y a la vez es la expresión estética del edificio, comunicandando de forma explícita una intención de sustentabilidad visual (Evans, 2010).

El uso de envolventes verdes en la construcción desde una perspectiva ecológica, resulta relativamente reciente. Si bien existen estudios e investigaciones de carácter científico sobre muros y techos verdes que permiten evaluar como positiva su efectividad, en función del clima y las demás condicionantes específicas, su aplicación sigue siendo muy baja, existiendo muy pocos ejemplos en la ciudad de Resistencia.

A diferencia de los edificios, que permanecen inertes, los objetos vivos responden al ambiente y son capaces de adaptarse a las cambiantes condiciones del clima (Armstrong, 2012). Las envolventes en la naturaleza son superficies multifuncionales que surgen de una compleja interacción entre la morfología superficial y las propiedades físicas y químicas del organismo biológico como respuesta de adaptación al medio.

La falta de adaptación de los edificios, con soluciones estáticas en fachadas, frente a factores ambientales cambiantes se traduce en el $33 \%$ de las emisiones de carbono por parte del sector de la construcción. La clave está en la adaptación y por tanto una nueva arquitectura adaptativa es necesaria para mejorar el rendimiento energético (López, 2020).

A diferencia de otros elementos constructivos, las superficies vegetales son elementos vivos que interactúan con el ambiente y el edificio de maneras muy diversas, lo que supone efectos tan significativos como los siguientes:

- Estéticas: comunica de forma explícita la intención de diseño ambientalmente consciente.

- Ecológicas: actúa como un filtro natural del aire. Las bacterias en las raíces de las plantas metabolizan las impurezas del aire tales como los compuestos orgánicos volátiles. Además, fija el dióxido de carbono y genera oxígeno.

- Higro - termo - acústicas: el "colchón" verde actúa como un aislamiento térmico de alto rendimiento y evita la ganancia solar excesiva dado que los rayos ultravioletas (UV) son absorbidos por este revestimiento exterior. Colabora con regulación de aspectos acústicos de la envolvente.

- Urbanas y paisajísticas: ayudan a conformar un espacio exterior agradable y en el que la sustentabilidad ambiental se materializa de forma explícita.

- Concientización ambiental: su uso alerta sobre la importancia de "reverdecer" nuestras construcciones y el espacio urbano.

- Innovación tecnológica - ambiental: resulta un tema de investigación, desarrollo e innovación tecnológica.

- Factibilidad de aplicarse en remodelaciones: es factible su uso en remodelación de edificios existentes ya sean estos contemporáneos o de diferentes épocas de construcción (desde edificios históricos con valor patrimonial a edificios viejos que carecen del mismo) reverdeciendo las ciudades.

- Reducción del efecto isla de calor urbano.

- Regulación del ciclo hidrológico.

- Protección y fomento de la biodiversidad en el entorno urbano.

- Beneficios sociales y psicológicos. 


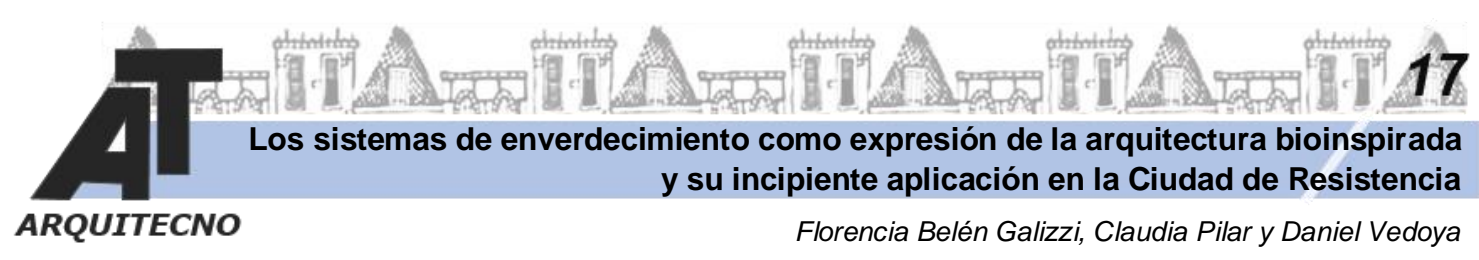

Tipos de Sistemas de Enverdecimiento Verticales

Los Sistemas de Enverdecimiento, se pueden clasificar de acuerdo a su sustrato y estructura.

\section{Clasificación de acuerdo al sustrato}

-Sistemas de Enverdecimiento Hidropónicos: son aquellos en los cuales los nutrientes de las especies vegetales se disuelven en el agua y se proporcionan a las mismas por medio de sus raíces. La palabra "hidropónico" se deriva de las palabras griegas hydro, que significa agua, y ponos, que significa trabajo. En este caso lo que se hace es partir y entender el concepto del "cultivo hidropónico" para convertirlo en una estrategia pasiva en la Arquitectura.

Utilizan un sustrato inerte que puede ser fieltro no tejido de poliamida, polietileno o poliéster, lana de roca y espumas técnicas, como poliuretano y poliurea, los cuales requieren abono continuo. Actualmente existe una gran variedad de formas y tipos desarrollados para este sistema, pero en general están formados por lo siguiente: 1. Pequeñas canastas donde se colocan las plantas y las raíces cuelgan para ser nutridas; 2. Estructura sólida y compacta y 3 . Sistema de riego constante.

-Sistemas de Enverdecimiento Aeropónicos: en este tipo de sistemas las especies vegetales se cultivan en un entorno aéreo o de niebla sin hacer uso del suelo. El término "aeropónico" se deriva de las palabras griegas aero, que significa aire, y ponos, que significa trabajo.

Las especies vegetales se desarrollan suspendidas en el aire y se le deben proporcionar los nutrientes por medio de rociadores, para lo cual se utilizan bombas de presión.

Son menos utilizados, pero forman parte de la clasificación ya que es una manera distinta de utilizar el sustrato para las raíces.

-Sistemas de Enverdecimiento Orgánicos: estos son característicos porque las raíces crecen en un medio artificial armado, utilizando un sustrato orgánico sin necesidad de aporte de abono excesivo. Es recomendado para superficies pequeñas, ya que su durabilidad es escasa, porque el sustrato se va degradando y requiere sustitución. Los nutrientes también se pueden aportar vía riego en mayor o menor porcentaje, pero no son tan imprescindibles para el funcionamiento por la mínima capacidad de retención que posee (D`Elia, Pilar y Morán 2019). Ver Figura 1.

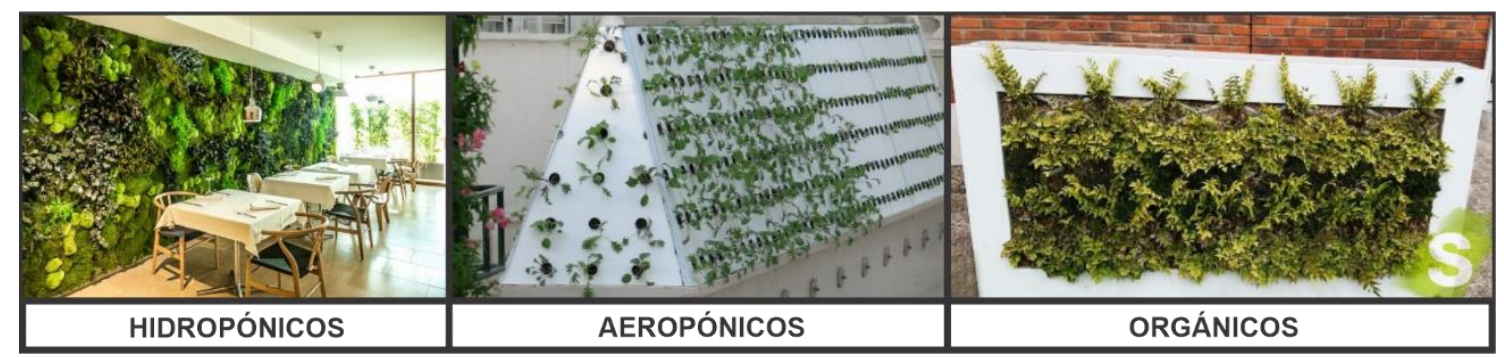

Figura 1: Clasificación de los Sistemas de Enverdecimiento de acuerdo al sustrato. Fuente: Reelaboración propia en base a imágenes de HidroJardín (2020), OkDiario (2018) y SingularGreen (2020, a).

\section{Clasificación de acuerdo a su estructura}

Sistemas de Enverdecimiento Vertical Natural (Figura 2): se caracterizan porque no cuenta con una estructura independiente al edificio, es decir sus métodos de sustentación lo constituyen los paramentos verticales de la obra. Podemos encontrar dos tipos: 


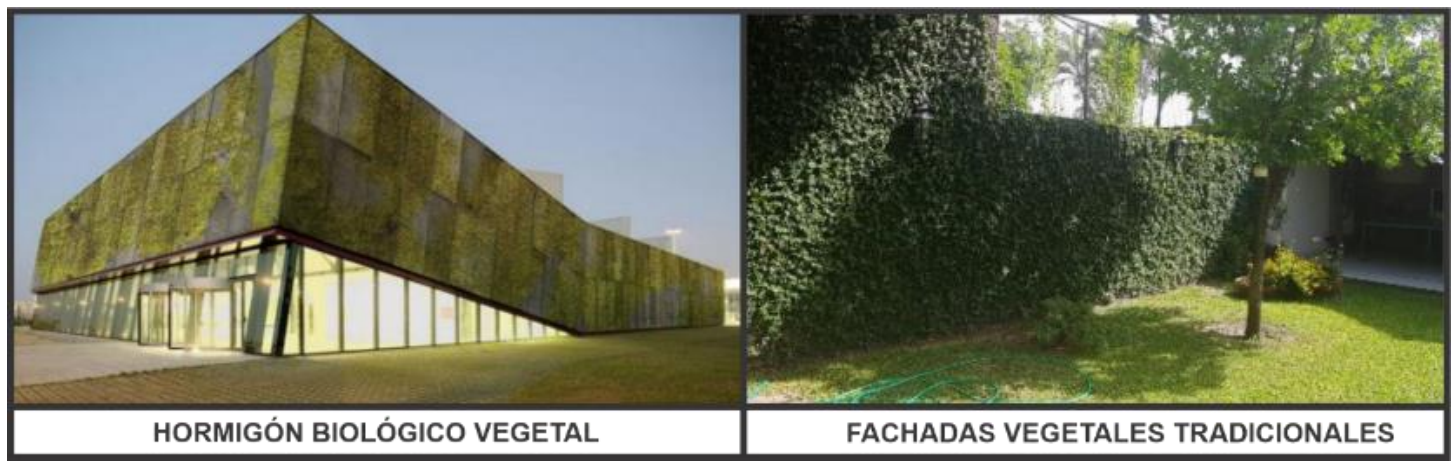

Figura 2: Sistemas de Enverdecimiento Natural. Fuente: Elaboración propia en base a imágenes de la Universidad Politécnica de Catalunya (2016) y Vivienda familiar de Resistencia, ubicada en García Merou 456.

- Hormigón Biológico Vegetal: en este caso se presenta una solución que cumple la función de revoque estructural y de revestimiento. No solo se está resolviendo la materialización del paramento, sino que, además, se incorpora el verde como terminación exterior. En este tipo de sistemas, los organismos crecerían directamente en la superficie del hormigón, lo que facilita su puesta en obra y mantenimiento, haciéndolo apto tanto para nuevas construcciones como para rehabilitación (Figura 2 a la izquierda).

-Fachadas Vegetales Tradicionales: en este tipo de sistemas, las plantas utilizan una superficie vertical existente y se extienden en ella desarrollando su crecimiento. Utilizan el paramento solamente como apoyo, ya que no reciben nutrientes ni humedad del mismo. Se apoyan en los mismos mediante raíces aéreas que pueden penetrar en grietas o juntas. En el caso que no posean raíces aéreas, se adhieren mediante zarcillos adhesivos (Figura 2 a la derecha).

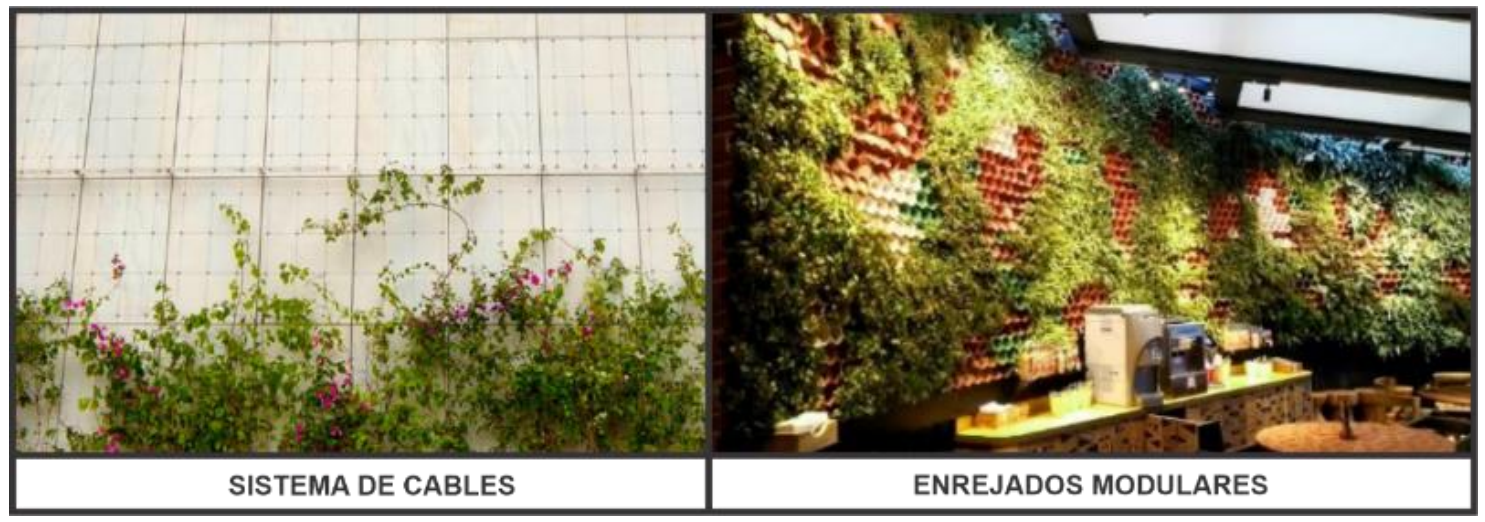

Figura 3: Sistemas de Enverdecimiento Doble Piel. Fuente: Reelaboración propia en base a imágenes de Jakob (2014) y Singular Green (2020, b).

-Sistemas de Enverdecimiento Doble Piel: requieren de elementos estructurales, portantes y de sujeción para su montaje y colocación, como así también de sistemas apartes que aseguren el mantenimiento de las especies vegetales. El objetivo es crear una segunda piel o pantalla entre la piel del edificio y el ambiente exterior (Navarro Portilla, 2013).

-Sistema de cables: el desarrollo de los jardines se da por medio de cables y varillas de acero inoxidable, con un conjunto de piezas accesorias, que dependerá del peso que deberá soportar la estructura, al igual que sus elementos de anclaje van a estar en función del material de la fachada (Figura 3 a la izquierda).

-Enrejados modulares: consisten en sistemas tridimensionales, formados por contenedores, o bien como lo dice su nombre, por enrejados a base de perfiles y chapas de acero inoxidable, permitiendo que se acoplen a las tipologías de las fachadas, pudiendo sus maceteros encontrarse de manera horizontal, vertical o bien inclinados (Figura 3 a la derecha). 


\section{Caso 1: Torre Alvear}

Edificio construido mediante el programa PROCREAR (Programa de Crédito Argentino del Bicentenario para la Vivienda Única Familiar, creado en el 2012) ubicado en Marcelo T. de Alvear y Liniers. Implementa la tipología de enrejados modulares, en el $2^{\circ}$ y $3^{\circ}$ nivel y la Zona Terraza de Expansión del edificio. El diseño de enrejado se propone sobre las fachadas Noroeste y Noreste, con especies autóctonas o de buena adaptación al clima de arbustos y enrederas.

Las plantas seleccionadas son arbustos y enredaderas, de crecimiento moderado a rápido, disponibles en la zona y resistentes a las condiciones de asoleamiento, vientos y lluvias preponderantes. Poseen un aspecto lluvioso. Las especies son de follaje perenne, en su mayoría denso, pasando por diferentes tonalidades de verde con flores blancas.

Cada una de las especies está ubicada para generar movimientos visuales, por sus diversos periodos de floración, concentrándose la mayor cantidad, en las estaciones de primavera y verano.

El sistema entonces, está formado por lo siguiente:

1. Estructura: caño estructural rectangular, malla electrosoldada en el cerco galvanizado y cable de acero.

2. Maceteros: los arbustos se ubican en maceteras jardineras de $100 \times 20 \times 40 \mathrm{~cm}$, en el $4^{\circ}$ piso y la Zona Terraza de Expansión del edificio. Las enredaderas se ubican en maceteras cubicas de $50 \times 50 \times 50 \mathrm{~cm}$ en el $1^{\circ}, 2^{\circ}$ y $3^{\circ}$ basamento. Las macetas son de fibrocemento y plástico rotomodelado.

3. Sistema de riego: caño de polietileno de baja densidad y manguera de pvc reforzada.

\section{Caso 2: Nebraska Bar}

El bar se encuentra ubicado en Laprida 88 y utiliza el Sistema de cables.

La fachada que incluye un jardín vertical se realizó en el marco de la refuncionalización del bar, a cargo de Cualitá Arquitectura. Para el aprovisionamiento y asesoramiento de las especies vegetales participo el emprendimiento de Hijas del Monte.

En la fachada y acceso al interior del bar, se plantea un sistema de jardín vertical por medio de cables de acero sobre un paramento existente.

Las especies empleadas fueron enredaderas, proveídas por Vivero Los Teros y su colocación, mantenimiento y cuidados por parte de Hijas del Monte.

El Sistema de Cables diseñado por Cualitá está estructurado de la siguiente manera:

1. Elementos de fijación superior: tuercas ciegas de acero inoxidable.

2. Cable individual: cable tensor orientado de manera vertical y espaciados alrededor del paramento curvo, actuando de guía de las especies vegetales.

3. Aprieta cables en cruz: mantienen los cables en su posición.

4. Elemento de fijación inferior: tuerca ciega con cabeza plana soldada.

5. Macetero de cemento: contiene el sustrato y el nacimiento de las especies vegetales.

El sistema de cables con sus enredaderas aporta un agregado visual y estético al ingreso, denotando el valor sostenible y amigable con su entorno, a la vez que representa lo local al utilizar especies por proveedores de la región.

Asimismo, es altamente resistente a la corrosión y su mantenimiento es relativamente barato ya que las especies elegidas soportan los agentes climáticos de la región.

\section{Caso 3: Bronx Bar}

Otro ejemplo local, es el Sistema Hidropónico ubicado en el interior del bar Bronx. Se encuentra ubicado en Liniers 390, en diagonal a la Plaza 12 de Octubre y próximo al centro de la Ciudad de Resistencia.

Nuevamente a cargo de Cualitá Arquitectura e Hijas del Monte, la refacción y refuncionalización de Bronx incluye en su interior un cuadro verde basado en un Sistema Hidropónico. 


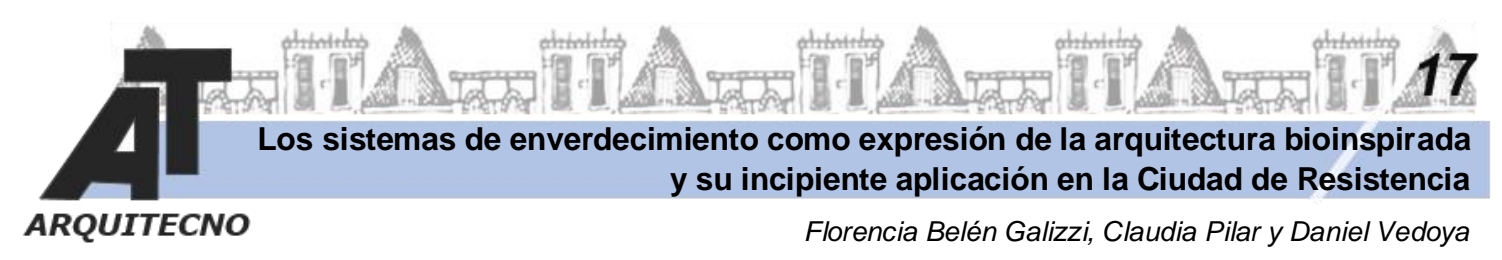

EI SE utilizado fue proyectado por Cualitá y materializado a través de Ecosistemas Verticales por parte de la microempresa Hijas del Monte.

Se trata de un Sistema Hidropónico, a partir del cual se generan las condiciones óptimas para el desarrollo y evolución de las plantas, garantizando mantenimientos mínimos (Hijas del Monte, 2020).

Las especies utilizadas para este cuadro de 5,5 metros de largo fueron cuatro tipos de Filodendro, Syngonio en tres colores, Aglaonemas monstruosas y melena de Potus. El Ecosistema Vertical está compuesto por lo siguiente:

1. Estructura: cuadro metálico que se fija al paramento.

2. Micro placa plástica de PVC.

3. Fieltro de geotextil con sistema de bolsillos.

4. Especies vegetales.

Las especies utilizadas fueron seleccionadas de acuerdo al requerimiento de necesitar el menor riego posible, convirtiendo de esta manera al cuadro en un sistema con mínimo mantenimiento y solamente control y poda del crecimiento de las especies.

Por otro lado, el prescindir del riego constante asegura mantener el entorno limpio (al encontrarse el cuadro en altura en un sector de mesas del bar) y no implica la colocación de sistemas de recolección de agua.

\section{Entrevistas a profesionales intervinientes}

Con el objetivo de clarificar las experiencias locales acerca del implemento del verde, se realizaron entrevistan de tipo semiestructuradas a dos emprendimientos pioneros que actualmente se encuentran trabajando con los sistemas de enverdecimiento en la Ciudad de Resistencia.

Por la empresa "Hijas del Monte", se entrevistó a Corina Capkauskas, abogada de profesión y emprendedora por vocación. Si bien es quien se especializa en lo atinente a las plantas y los distintos sistemas, se trata de un emprendimiento colaborativo en el que se unen distintos oficios con el punto en común de la afinidad por y hacia las plantas y la naturaleza. Entre los aspectos más destacados de la entrevista se observa que aplican un sistema patentado, denominado

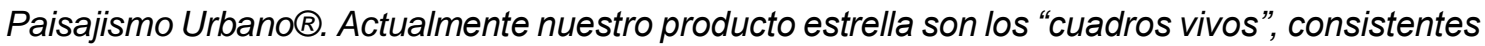
en pequeños jardines verticales portables, realizados en medidas predeterminadas, aptos para espacios interiores como exteriores. Son una propuesta basada en una composición viva que nace de la fusión de los colores y texturas proporcionadas por la vegetación que estos contienen, creados a partir de un diseño único, teniendo en cuenta la situación particular del entorno para el cual se requieren.

Luego se realizó la entrevista a "Siempre Verde- Diseño de Jardines", empresa familiar formada por Marina Ventura, Sarina Ventura y Juan Andrés Frangioli, hijo de Marina y $3 / 4$ empleados ocasionales de acuerdo a la magnitud del trabajo a realizar. Entre los aspectos más destacados de la entrevista se destaca los inicios Arrancamos hace 20 años como un hobby amando la naturaleza el color y la prolijidad en los jardines.... aprendimos transitando el camino... y fuimos creciendo al andar. No nos cruzamos de brazos, al contrario... hicimos cursos y nos actualizamos permanentemente. ¿La gente creyó en nosotros y no paramos de trabajar! ¡Ahora además hacemos jardines verticales!". Trabajan con distintos tipos de SE por ejemplo el hidropónico. Con este sistema tuvimos muy buenos resultados ya que si todo el sistema funciona los jardines perduran en el tiempo y con bajo consumo de agua y fertilizantes. 


\section{RESULTADOS}

Una vez realizada la identificación y análisis de los ejemplos, se arriban a las siguientes conclusiones:

- A nivel local se están dando los primeros pasos en el implemento del verde en techos y paredes, pero si bien se observaron numerosos ejemplos de viviendas con el sistema de Fachadas Vegetales Tradicionales, las mismas se dan debido al avance de las especies vegetales de hierbas sobre los paramentos y no por una decisión de diseño.

- Los pocos ejemplos que se observan utilizan sistemas hidropónicos, enrejados modulares y en muchos casos cuadros vivos.

- Se observa un incremento sostenido de la inclusión del verde en la arquitectura, principalmente en refacciones y refuncionalizaciones, referidos al sector comercial y la residencia.

- La Ciudad de Resistencia cuenta con numerosos proveedores locales para los suministros y mantenimiento de las especies vegetales. Esto quiere decir que no existen condicionantes a la hora de proyectar y diseñar estas envolventes.

Como se planteó al inicio del presente trabajo, se pretendía abordar la temática de las envolventes, analizándolas desde el punto de vista tecnológico para contribuir a que las mismas sean consideradas como estrategias de aplicación en la región para facilitar el confort higrotérmico y explotar al máximo los beneficios urbanos, sociales y ambientales que las mismas proveen. Por lo tanto, se presentan a continuación una serie de pautas a considerar a la hora de aplicar el verde en paredes.

- Evaluar las condiciones del soporte. Tener en cuenta el material de construcción para la aplicación de la membrana impermeable para los jardines verticales.

- A la hora de elegir el SE a emplear, considerar el nivel de mantenimiento y accesibilidad, ya que si son obras patrimoniales donde se requiere el menor impacto y alta durabilidad, se recomiendan SE de bajo mantenimiento.

- Es primordial proteger siempre a la obra del agua, la humedad y los agentes atmosféricos, para prolongar la vida útil de la misma, por lo cual sistemas doble piel con cámara de aire son los más óptimos.

- Diseñarlos teniendo en cuenta su ciclo de vida, priorizando de cumplir un ciclo "de la cuna a la cuna".

- A la hora de seleccionar las especies vegetales, realizarlo en función del entorno a implantarse, teniendo presente que las mismas poseen un comportamiento durante todo el año y que cada especie se adapta de una u otra manera. No seguir modas o especies tipo que luego culminan en sistemas descuidados o dejados de lado.

\section{CONCLUSIONES}

A partir de la sistematización de las distintas posibilidades que permite el verde de materializarse tecnológica-constructivamente, se logró abordar a una serie de pautas que permitan facilitar su implementación como estrategía de aprovechamiento pasivo para el ahorro energético y aislamiento térmico de los edificios nuevos y la remodelación de los existentes.

La aplicación del verde es una práctica ampliamente difundida a nivel internacional, que tiene miras de comenzar a desarrollarse en nuestro país y que, a nivel regional, si bien se presentan contadas experiencias aisladas, esto se debe a que no está difundida la misma como práctica tecnológica con amplias ventajas, sino más bien es vista como un ornamento, moda y/o añadido estético. 


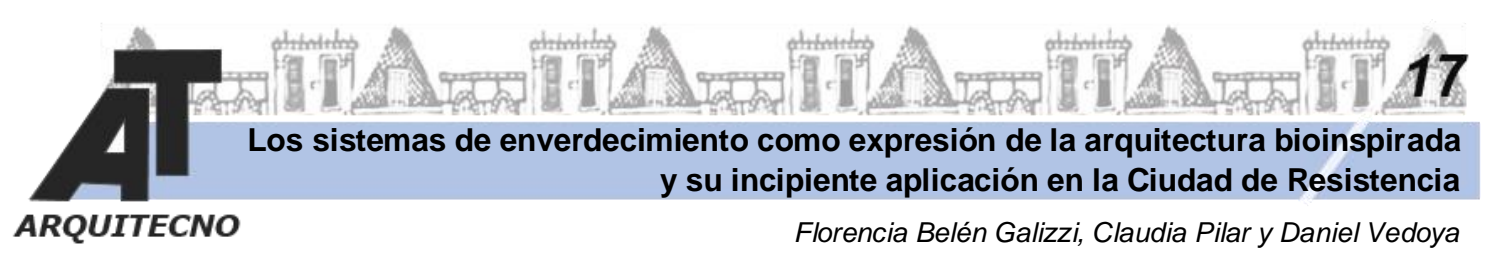

\section{BIBLIOGRAFÍA}

Armstrong (2012). La adaptación en la naturaleza. Recuperado de: https://laboratoriobiomimetico.com/

Benyus, J. (2012). Biomimesis. Cómo la ciencia innova inspirándose en la naturaleza. Barcelona: Tusquets Editores S.A.

Braungart, M. y Mcdonough, W. (2005). Cradle to cradle. Rediseñando la forma en que hacemos las cosas. Madrid: McGraw Hill.

D' Elia, María del Rosario; Pilar, Claudia y Morán, Rosanna (2019). Muros verdes para las condiciones ambientales de la Región Nordeste Argentina. Revista ARQUITECNO N 14. Noviembre de 2019. Ediciones del ITDAHu. Corrientes, Argentina. Página 55 a 63. ISSN 0328-0896.

Czajkowski, Jorge y Gómez, Analía (2009). Arquitectura sustentable. Ed. Clarín. Buenos Aires, Argentina.

Evans, Julián (2010). Sustentabilidad en Arquitectura. Consejo Profesional de Arquitectura y Urbanismo. Buenos Aires.

Hidrojardín (2020). La vegetación. Un elemento decorativo esencial. Recuperado de: https://www.hidrojardin.info/blog-informativo-decoracion-vegetacion-bar-restaurante/

Hijas del Monte (2020). Ecosistemas Verticales. Recuperado de: https://amanooficial.com/productos/vegetacion-y-macetas/plantas-de-interior/1311

Jakob (2014). Green Solutions. Recuperado de: https://www.jakob.com/chen/downloads/catalogs

Lopez, M (2020). Nuevas fronteras biológicas. Recuperado de: https://laboratoriobiomimetico.com/fronterasbiologicas/

Navarro Portilla, J. (2013). Los jardines verticales en la edificación. Trabajo final de máster en edificación, Escuela Técnica Superior Ingeniería de Edificación, Universidad Politécnica de Valencia.

NewGreen (2019). Nuñez Jardín Vertical con gaviones en medianera. Portfolio Jardines Verticales. Recuperado de: https://www.newgreen.com.ar/obras-realizadas/nunez-jardinvertical-medianeral

Ok Diario (2018). Los cultivos aeropónicos y la ciencia de la aeropónia. Recuperado de: https://okdiario.com/curiosidades/cultivos-aeroponicos-2882119

Singular Green (2020, a). Jardín vertical para interior o un pequeño jardín en casa. Recuperado de: https://www.singulargreen.com/jardines-verticales/\#jv3.1

Singular Green (2020, b). Jardín Vertical EcoBin, Nando's Kitchen, Londres. Dossier comercial. Revisión 2020. Jardines Verticales. Recuperado de: https://www.singulargreen.com/portalde-descargas/

Universidad Politécnica de Catalunya (2016). Nuevo concepto de fachada verde: el "hormigón biológico" como el futuro de las fachadas ecológicas. Recuperado de: https://arquitecturayempresa.es/noticia/nuevo-concepto-de-fachada-verde-el-hormigonbiologico-como-el-futuro-de-las-fachadas

Urbanolismo (2019). Fachada vegetal del Palacio de Congresos de Vitoria-Gasteiz. Recuperado de: $\quad$ https://www.urbanarbolismo.es/blog/fachada-vegetal-del-palacio-de-congresos-devitorial

Vedoya, D. y Prat, E. (2018). Introducción a la biomímesis aplicada a la arquitctura. ADNea Revista de Arquitectura y Diseño del Nordeste argentino. Vol $6-$ N. ${ }^{\circ} 6$. P. 149. 